\title{
Thyrotropin suppression therapy for papillary thyroid carcinoma with a huge recurred neck lymph node
}

\author{
Jung Bum Choi', Dong-il Kim², Hyun-june Paik², Seung Joo Lee², Chang Shin Jung², Seok Kyung Kang², Youn Joo Jung², \\ Hyun Yul Kim ${ }^{3}$ \\ 'Department of Surgery, Pusan National University Hospital, Busan; \\ ${ }^{2}$ Department of Surgery and ${ }^{3}$ Research Institute for Convergence of Biomedical Science and Technology, Pusan National University Yangsan Hospital, \\ Yangsan, Korea
}

Differentiated thyroid cancer (DTC) originating from thyroid tissue is affected by thyrotropin (TSH). TSH suppression therapy is usually recommended after thyroidectomy in cases of DTC. A 57-year-old woman who harbored a very huge recurred lymph node underwent TSH suppression therapy because of the risk of surgical complications. After TSH suppression, the huge neck lymph node exhibited a response and decreased in size. She had been followed up for 144 months. TSH suppression therapy could be considered as an alternative treatment option in a recurred DTC patient with a high perioperative risk.

Keywords: Papillary thyroid carcinoma, Thyrotropin, Active surveillance, Locoregional neoplasm recurrence, Case report

\section{INTRODUCTION}

Differentiated thyroid cancer (DTC) originates primarily from thyroid follicular cells and is affected by thyrotropin (TSH), similar to normal thyroid cells [1-4]. Based on this fact, TSH suppression therapy, which suppresses the growth of DTC tissue by suppressing TSH, is used for the postoperative management of DTC [2-4]. In cases of recurrence and metastasis of DTC, TSH suppression therapy may be applied in patients who cannot undergo surgery [2]. We report a case of a huge recurred neck lymph node of papillary thyroid cancer that responded to TSH suppression therapy.

Received: Jun 30, 2020 Revised: Oct 13, 2020 Accepted: Oct 26, 2020 Correspondence to: Dong-il Kim

Department of Surgery, Pusan National University Yangsan Hospital, 20 Geumo-ro, Mulgeum-eup, Yangsan 50612, Korea

Tel: +82-55-360-2124, Fax: +82-55-360-2154

E-mail: led117@naver.com

ORCID: Jung Bum Choi (https://orcid.org/0000-0002-5225-3929), Dong-il Kim (https://orcid.org/0000-0001-9874-1322), Hyun-june Paik (https://orcid.org/00000002-2749-4165), Seung Joo Lee (https://orcid.org/0000-0001-5100-0017), Chang Shin Jung (https://orcid.org/0000-0002-2945-4191), Seok Kyung Kang (https:// orcid.org/0000-0002-4119-9445), Youn Joo Jung (https://orcid.org/0000-00029647-8556), Hyun Yul Kim (https://orcid.org/0000-0001-7717-7734)

Copyright $@ 2020$ Korean Society of Surgical Oncology

This is an Open Access article distributed under the terms of the Creative Commons Attribution Non-Commercial License (http://creativecommons.org/licenses/by-nc/4.0) which permits unrestricted non-commercial use, distribution, and reproduction in any medium, provided the original work is properly cited.
This study was approved by the Institutional Review Board of Pusan National University Yangsan Hospital (IRB No. 05-2020-104). The informed consent was waived.

\section{CASE REPORT}

A 57-year-old woman presented with a lump in her neck. The patient had undergone right thyroid lobectomy for papillary thyroid cancer 17 years prior in another hospital. There were no medical records about that surgery. She also did not undergo follow-up or receive any other treatment.

There was a hoarseness in her voice and a lump on her neck from 3 years prior, but she remained untreated; from 1 month prior, the lump in her neck enlarged and she visited our hospital.

A fine-needle aspiration test of the left neck level IV lymph node led to the diagnosis of metastatic papillary thyroid cancer. On computed tomography (CT) of the neck, a calcified nodule $3.5 \times$ $3.0 \mathrm{~cm}$ in size in the left thyroid gland (Fig. 1A), lymph node $5.0 \times$ $4.5 \mathrm{~cm}$ in size located between the esophagus and aorta along the trachea behind the sternum (Fig. 2A), and a $6.6 \times 4.4 \mathrm{~cm}$-sized lymph node in the left neck area were observed (Fig. 3A). There was no lung metastasis on chest CT. Moreover, multiple lymph nodes suspected of recurrence were observed in the left lateral neck region. On esophageal ultrasonography performed for preoperative assessment, the metastatic lymph node existing between the esophagus and trachea was observed to be invading the esoph- 

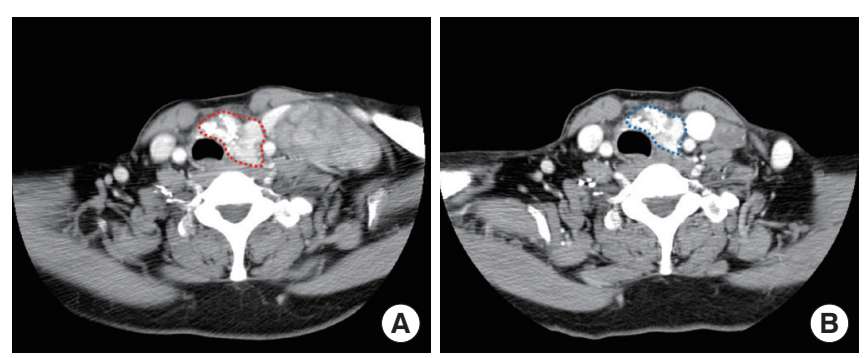

Fig. 1. Computed tomography (CT) image of left thyroid gland. (A) An initial CT image shows a $3.5 \times 3.0-\mathrm{cm}$ sized calcified nodule (red dot line) in the left thyroid gland. (B) Left thyroid nodule (blue dot line) decreased to $2.9 \times 2.0 \mathrm{~cm}$ in size 16 months after thyrotropin suppression.
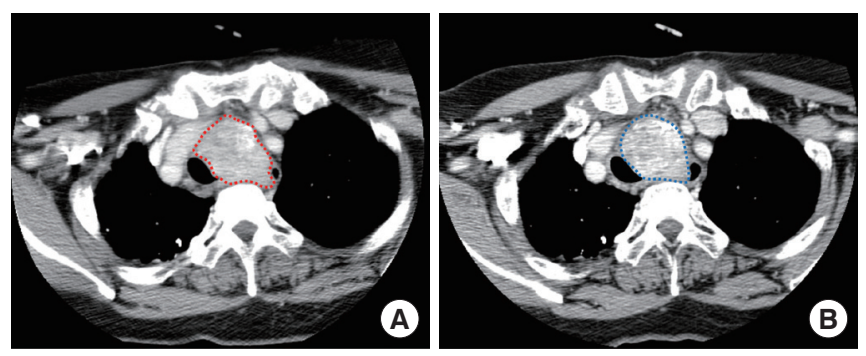

Fig. 2. Computed tomography (CT) image of enlarged mediastinal lymph node. (A) A lymph node (red dot line) $5.0 \times 4.5 \mathrm{~cm}$ in size located between the esophagus and aorta at CT image. (B) CT image shows a decreased $4.5 \times 4.0-\mathrm{cm}$ sized lymph node (blue dot line) in mediastinum 16 months after thyrotropin suppression.

agus.

For radical surgery, completion thyroidectomy, left cervical modified radical neck dissection, esophagectomy, and intra-thoracic aortic lymph node dissection were needed. The patient was advised to undergo surgery, adjuvant radiation therapy, and radio-iodine ablation, but after learning of the risks and possible complications of the surgery, she decided not to undergo any kind of surgery or additional invasive treatment.

First, we decided to initiate TSH suppression therapy, monitor her response to the treatment, and then consider whether additional treatment was available. At the time of the visit, the patient's TSH level was $2.55 \mu \mathrm{IU} / \mathrm{mL}$, which was in the normal range, but $100 \mu \mathrm{g}$ of levothyroxine (L-T4) was prescribed once a day to suppress TSH. Based on a blood test performed 1 month after prescribing L-T4, her TSH level decreased to $0.01 \mu \mathrm{IU} / \mathrm{mL}$, and the size of the lump in the neck decreased slightly.

Neck CT performed 3 months after prescribing L-T4 showed a decrease in the size of most of the lymph nodes that had been enlarged in the previous test. We determined that TSH suppression therapy was effective for our patient. To further suppress TSH, the $\mathrm{L}$-T4 dose was increased to $150 \mu \mathrm{g}$.
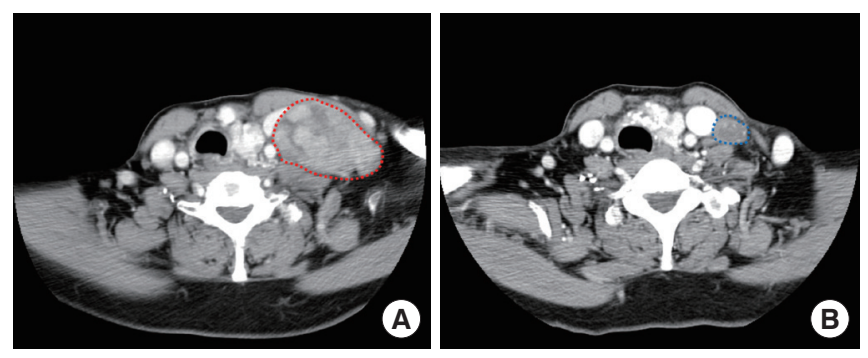

Fig. 3. Computed tomography (CT) image of a huge recurred neck lymph node. (A) An initial CT image shows a $6.6 \mathrm{~cm}$-sized huge recurred neck lymph node (red dot line). (B) The huge recurred lymph node (blue dot line) decreased to $2.0 \mathrm{~cm}$ in size 16 months after thyrotropin suppression.

On neck CT, which was performed 16 months after initiating TSH suppression therapy, the left thyroid nodule reduced to $2.9 \times$ $2.0 \mathrm{~cm}$ in size (Fig. 1B), and the size of the lymph nodes located between the trachea, esophagus, and aorta also reduced to $4.5 \times 4.0$ $\mathrm{cm}$ in size (Fig. 2B).

In particular, the lymph nodes in contact at level IV of the left neck showed a significant reduction in the largest diameter from 6.6 to $2.0 \mathrm{~cm}$ (Fig. 3B). Since then, the metastatic lymph nodes have remained stable without further changes in size based on annual CT.

Currently, she has been followed up with TSH suppression therapy for 144 months.

\section{DISCUSSION}

It is widely known that DTC mostly has a positive course and favorable prognosis [5]. However, in rare cases, recurrence in adjacent lymph nodes can occur even after surgery, and if proper diagnosis or treatment is not achieved, recurred lymph nodes may increase in size or metastasize to other organs $[2,6]$.

TSH stimulates the growth and proliferation of thyroid cancer cells as well as normal thyroid cells. Some epidemiologic and animal studies show that higher TSH levels are associated with the incidence and severity of DTC [7]. Based on these results, TSH suppression therapy was applied to the postoperative management of DTC patients. Now, it is well known that TSH suppression therapy is effective in reducing cancer recurrence in patients with DTC undergoing surgery, and the American Thyroid Association guidelines recommend TSH suppression therapy to maintain adequate TSH levels depending on the risk of thyroid cancer [2-4].

If recurred lymph nodes are found in patients with DTC, the first-line treatment is surgical resection, followed by additional treatment such as radioactive iodine ablation, external beam radiation therapy, or tyrosine kinase inhibitors [2,6]. TSH suppression 
therapy may be considered as an adjuvant therapy after surgical treatment for recurred lymph nodes of thyroid cancer, but not as an initially prioritized treatment $[2,6]$. However, in patients with asymptomatic stable recurred lymph nodes, it may be considered as a treatment option [2].

In this case, the patient did not wish to undergo surgery after learning of the risks and complications of the surgery. Therefore, we recommended active surveillance accompanied by TSH suppression therapy to the patient.

There is one case reported in which a recurred lymph node in a patient with DTC regressed spontaneously without additional treatment. In that case, the size of the metastatic lymph node was small $(8 \mathrm{~mm})$, and it was thought that the effect of TSH suppression cannot be ruled out due to the taking of L-T4 after undergoing total thyroidectomy [8]. Our patient did not receive L-T4 after right thyroid lobectomy, and her TSH level was in the normal range and did not fall within the category of requiring TSH suppression. TSH suppression was initiated by prescribed L-T4. Since then, the size of the recurred lymph nodes had decreased, but the hoarseness in her voice had not improved, and the calcified thyroid nodules and calcified lymph nodes also had not changed.

The thyroglobulin (Tg) level did not change significantly in our patient. The existing left thyroid gland and calcified lymph nodes remained intact; thus, the Tg level was not likely to change significantly.

The treatment of choice for recurred lymph nodes in cases of DTC is surgical resection; if the operation is not possible for various reasons, TSH suppression therapy could also be considered an alternative treatment option.

Moreover, if a patient responds well to TSH suppression, longterm active surveillance therapy with TSH suppression may be continued.

We report a case of a huge recurred lymph node that was treated with TSH suppression therapy in a patient who underwent active surveillance for 144 months.

\section{CONFLICT OF INTEREST}

No potential conflict of interest relevant to this article was reported.

\section{REFERENCES}

1. Hermus AR, Huysmans DA. Treatment of benign nodular thyroid disease. N Engl J Med 1998;338:1438-47.

2. Haugen BR, Alexander EK, Bible KC, Doherty GM, Mandel SJ, Nikiforov YE, et al. 2015 American Thyroid Association management guidelines for adult patients with thyroid nodules and differentiated thyroid cancer: The American Thyroid Association Guidelines Task Force on thyroid nodules and differentiated thyroid cancer. Thyroid 2016;26:1-133.

3. Wang PW, Wang ST, Liu RT, Chien WY, Tung SC, Lu YC, et al. Levothyroxine suppression of thyroglobulin in patients with differentiated thyroid carcinoma. J Clin Endocrinol Metab 1999;84: 4549-53.

4. Biondi B, Cooper DS. Benefits of thyrotropin suppression versus the risks of adverse effects in differentiated thyroid cancer. Thyroid 2010;20:135-46.

5. Pellegriti G, Scollo C, Lumera G, Regalbuto C, Vigneri R, Belfiore A. Clinical behavior and outcome of papillary thyroid cancers smaller than $1.5 \mathrm{~cm}$ in diameter: study of 299 cases. J Clin Endocrinol Metab 2004;89:3713-20.

6. Caron NR, Clark OH. Papillary thyroid cancer: surgical management of lymph node metastases. Curr Treat Options Oncol 2005; 6:311-22.

7. Biondi B, Cooper DS. Thyroid hormone suppression therapy. Endocrinol Metab Clin North Am 2019;48:227-37.

8. Shim J, Rao J, Yu R. Spontaneous regression of metastatic papillary thyroid cancer in a lymph node. Case Rep Endocrinol 2018;2018: 5873897. 